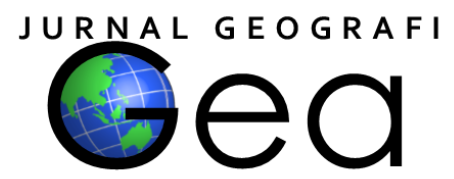

\title{
PADANG LAMUN SEBAGAI EKOSISTEM PENUNJANG KEHIDUPAN BIOTA LAUT DI PULAU PRAMUKA, KEPULAUAN SERIBU, INDONESIA
}

\author{
Muzani Jalaluddin', Ika Nur Octaviyani², Aufeeazzahra Nurani Praninda Putri ${ }^{3}$, Winny \\ Octaviyani $^{4}$, Iqbal Aldiansyah ${ }^{5}$ \\ 1,2,3,4,5 Program Studi Pendidikan Geografi, Universitas Negeri Jakarta \\ ${ }^{1}$ muzani@unj.ac.id, ${ }^{2}$ ikanuroctaviyani4@gmail.com, ${ }^{3}$ aufeeazhrnpp@gmail.com, \\ 4winnyocta@gmail.com, ${ }_{5}$ ialdiansyah28@gmail.com
}

\begin{abstract}
Coastal ecosystems generally consist of 3 constituent components, namely seagrass, coral reefs, and mangroves. These three ecosystems make the area in the coastal area a relatively fertile and productive area. Seagrass are coastal ecosystems that have high biological productivity and play an important role in the ecological and physical functions of the environment in coastal areas. Ecologically, seagrass act as nursery ground, feeding ground for small fish, turtles, sea urchins, and other marine organisms, as well as shelter for various types of marine organisms. Physically, seagrass act as vegetation that maintains stability and holds sedimentation in coastal areas, reduces and slows wave movements, and occurs as a nutrient cycle, and it can be said that seagrass ecosystems are one of the ecosystems in the shallow sea that has high productivity. In addition, seagrass have a function that is no less important and is quite widely studied at this time, namely its function as carbon sinks or Blue Carbon (Karawoe, 2009). Seagrass ecosystems have an important role in supporting the life and development of marine organisms in shallow oceans, for example such as in Pramuka Island. Research on the role of seagrass as a supportive ecosystem for marine organisms in Pramuka Island was carried out with direct research into the field on December 6, 7 and 8, 2019. From the results of the research, we found that there were 4 types of seagrass in Pramuka Island, precisely in the eastern area in Pramuka Island, namely Cymodocea rotundata, Cymodocea serrulate, Enhalus acoroides, and Enhalus hemprichii. The four types of seagrasses have an important role in the seagrass ecosystems, especially in supporting the life of marine organisms in Pramuka Island.
\end{abstract}

Keywords: seagrass, marine organisms, Pramuka Island.

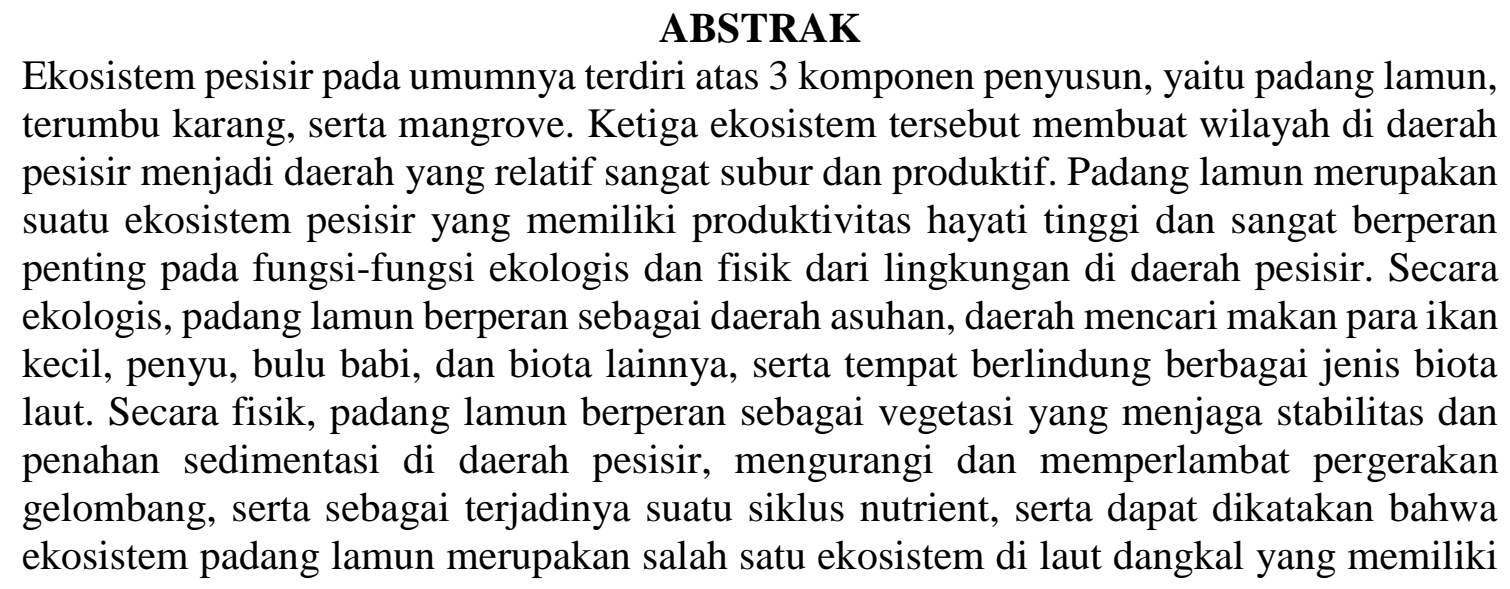


produktivitas tinggi. Selain itu, padang lamun memiliki fungsi yang tidak kalah penting dan cukup banyak diteliti pada saat ini, yaitu fungsinya sebagai penyerap karbon (carbon sink) atau Blue Carbon (Karawoe, 2009). Ekosistem padang lamun ini sangat memiliki peranan penting dalam penunjang kehidupan dan perkembangan biota laut di lautan yang dangkal, salah satu contohnya seperti di Pulau Pramuka ini. Penelitian mengenai peranan padang lamun sebagai ekosistem penunjang kehidupan biota laut di Pulau Pramuka ini dilakukan dengan penelitian langsung ke lapangan pada tanggal 6, 7, dan 8 Desember 2019. Dari hasil penelitian, kami menemukan bahwa ada 4 jenis lamun di Pulau Pramuka tepatnya di daerah timur di Pulau Pramuka, yaitu Cymodocea rotundata, Cymodocea serrulate, Enhalus acoroides, dan Enhalus hemprichii. Keempat jenis lamun ini memiliki peranan penting dalam ekosistem padang lamun terutama dalam menunjang kehidupan biota laut di Pulau Pramuka.

Kata kunci: padang lamun, biota laut, Pulau Pramuka.

\section{PENDAHULUAN}

Indonesia merupakan negara kepulauan yang memiliki potensi sumber daya laut yang begitu besar dan memiliki biodiveritas yang sangat tinggi. Saat ini, salah satu sumber daya laut yang diakui dan memiliki peranan yang begitu penting bagi kehidupan laut beserta biota lautnya selain terumbu karang dan mangrove yaitu padang lamun. Padang lamun di Indonesia memiliki luas sekitar 30.000 km2 dan berperan penting dalam ekosistem laut dangkal karena merupakan habitat ikan dan biota perairan lainnya (Nontji, 2005).

Padang lamun merupakan ekosistem perairan dangkal yang kompleks, memiliki produktivitas hayati yang tinggi. Oleh karena itu padang lamun merupakan sumberdaya laut yang penting baik secara ekologis maupun secara ekonomis (Rasheed et al., 1994). Fungsi ekologis padang lamun diantaranya adalah sebagai daerah asuhan, daerah pemijahan, daerah mencari makan, dan daerah untuk mencari perlindungan berbagai jenis biota laut seperti ikan, krustasea, moluska, echinodermata, dan sebagainya (Phillips dan Menez, 1988; Thomascik et al., 1997), tumbuhan padang lamun itu sendiri merupakan makanan penting dugong (Dugong dugon) dan penyu hijau (Chelonia mydas) (Lanyon et al., 1989) dan bertindak sebagai jebakan sedimen dan adanya siklus nutrient.

Banyak di antara biota laut yang memiliki nilai penting secara komersil dan rekreasi, pada stadia tertentu dalam siklus hidupnya sangat bergantung pada keberadaan ekosistem padang lamun. Seiring dengan meningkatnya aktivitas industri dan pembangunan di wilayah pesisir, maka tekanan ekologis terhadap ekosistem padang lamun juga meningkat, akibatnya berdampak terhadap rusaknya ekosistem tersebut dan menurunnya peranan-peranan ekologis yang diperankannya.

Padang lamun daerah tropis merupakan subjek dari perubahan temporal yang bervariasi secara musiman dan tahunan (Mellors et al., 1993). Kerusakan dan kehilangan yang luas dari padang lamun telah didokumentasikan dengan baik dan penyebabnya dapat karena bencana alam seperti badai, dan karena aktivitas manusia (Poiner et al., 1989). Aktivitas manusia yang dapat merusak ekosistem padang lamun diantaranya adalah pengerukan dan penimbunan atau reklamasi di wilayah pesisir sehingga menenggelamkan ekosistem tersebut. Adanya dermaga dan tempat pendaratan kapal atau perahu, penggunaan jaring pantai (beach seine) yang ditarik melalui ekosistem padang lamun, perburuan ikan duyung (dugong), adanya limbah pertanian dan pertambakan juga ikut berperan dalam merusak ekosistem padang lamun. (Fortes, 1990).

Mengingat besarnya peranan ekosistem padang lamun bagi kehidupan biota laut dan banyaknya ancaman-ancaman dari berbagai aktivitas manusia, industri, dan pembangunan terhadap rusaknya dan menurunnya peranan ekologis dari ekosistem padang lamun tersebut, maka usaha perlindungan dan pelestariannya melalui program manajemen dan konservasi padang lamun menjadi sesuatu yang harus dilakukan. Untuk keperluan manajemen dan konservasi diperlukan pemahaman yang baik mengenai ekologi mereka menyangkut sebaran jenis, kerapatan, 
persen penutupan dan jenis-jenis yang berassosiasi dengan padang lamun (Fortes, 1990).

\section{METODE PENELITIAN \\ Penentuan Lokasi Penelitian}

Penentuan lokasi penelitian dilakukan berdasarkan pengamatan visual kondisi padang lamun di bagian timur Pulau Pramuka yang mewakili kondisi keseluruhan padang lamun yang berada di seluruh penjuru Pulau
Pramuka. Dapat diketahui bahwa hampir di seluruh pesisir pantai Pulau Pramuka terdapat sebaran padang lamun, namun dalam penelitian ini di lihat kondisi padang lamun yang ada di bagian timur untuk mengetahui peranan padang lamun sebagai ekosistem penunjang kehidupan biota laut yang ada di daerah tersebut. Titik lokasi penelitian padang lamun ini di tinjau atau (track) melalui Avenza Maps agar terlihat jelas sebaran lokasinya (Gambar 1).

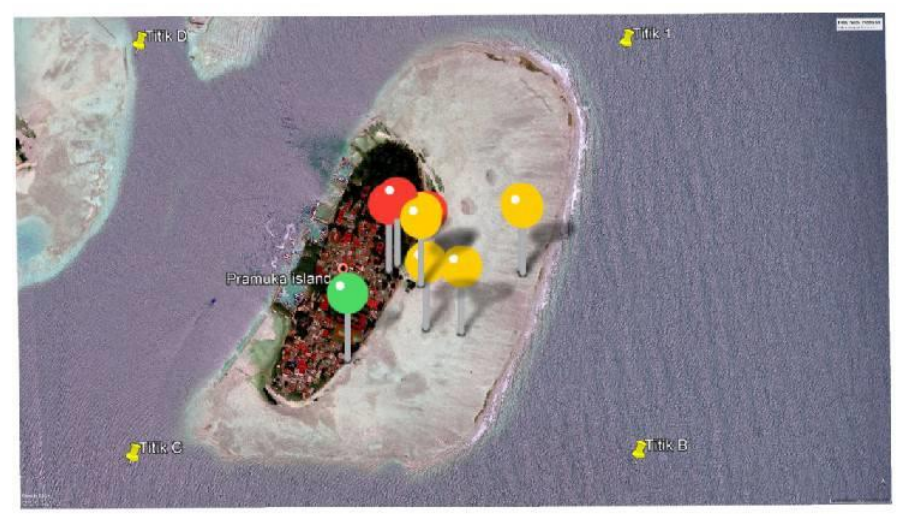

Gambar 1. Avenza Maps Pulau Pramuka.

\section{Metode Deskriptif Analitik}

Metode deskriptif analitik adalah suatu metode yang berfungsi untuk mendeskripsikan atau memberi gambaran terhadap objek yang diteliti melalui data atau sampel yang telah terkumpul sebagaimana adanya tanpa melakukan analisis dan membuat kesimpulan yang berlaku untuk umum (Sugiono, 2009:29).

\section{HASIL DAN PEMBAHASAN}

\section{Kondisi Padang Lamun di Pulau Pramuka}

Di seluruh dunia telah terindentifikasi 60 jenis Lamun. Di perairan Asia Tenggara terdapat 20 jenis lamun. Di Indonesia sendiri terdapat 15 jenis Lamun yang dapat dijumpai yaitu Enhalus acoroides, Cymodocea rotundata, Cymodocea serrulate, Halophila decipiens, Halophila ovalis, Halophila minor, Halophila spinulosa, Haludole pinifolia, Halodule uninervis, Syringodium isoetifolium, Thalassia hemprichii, Thalassodendron ciliatum, Halophila sulawesii, Halophila becarii dan Ruppia maritima.

Di Kawasan Taman Nasional Kepulauan Seribu terdapat 7 jenis Lamun yaitu Enhalus acoroides, Thalassia hemprichii, Cymodocea serrulata, Cymodocearotundata, Halophila ovalis, Syringodium isoetifolium, dan Halodule uninervis (BTNKpS 2008). Padang Lamun yang terdapat di hamparan pesisir Pulau Pramuka khusunya di bagian timur memiliki banyak manfaat yaitu sebagai produsen primer habitat biota laut, stabilisator dasar perairan, penangkap sedimen, dan pendaur hara yang dapat menciptakan air dengan kualitas yang jernih di sekitar perairan tersebut.

Di Pulau Pramuka kondisi perairannya relative tenang dengan substrat dasar nya terdiri dari pasir sehingga lamun tersebut dapat tumbuh subur dengan baik pada daerah tersebut. Kondisi lingkungan Pulau Pramuka yang tenang, menyebabkan terjadi nya akumulasi pasir yang tinggi pada substrat. Pada kondisi lingkungan yang demikian hanya spesies tertentu yang dapat tumbuh di Pulau Pramuka tepatnya di daerah timur di Pulau Pramuka, yaitu Cymodocea rotundata, Cymodocea serrulate, Enhalus acoroides, dan Thalasia hemprichii. 


\section{Distribusi Lamun di Pulau Pramuka bagian Timur}
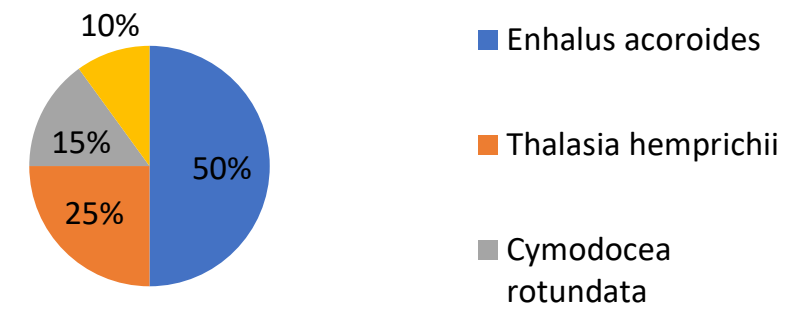

Gambar 2. Distribusi Padang Lamun di Pulau Pramuka Timur.

Berdasarkan diagram lingkaran tersebut jenis lamun yang memililki komposisi tertinggi yaitu Enhalus acoroides dengan persentasi mencapai 50\% sedangkan komosisi yang terendah yaitu jenis lamun Cymodocea serrulata $10 \%$. Lamun jenis Enhalus acoroides tersebut mendominasi lamun di bagian Timur Pulau Pramuka. Lamun tersebut tumbuh dengan subur dan baik di bagian Timur Pulau Pramuka. Hal ini karena bagian Timur Pulau Pramuka memiliki karakteristik substrat dan faktor lingkungan yang cocok untuk pertumbuhan jenis lamun tersebut.

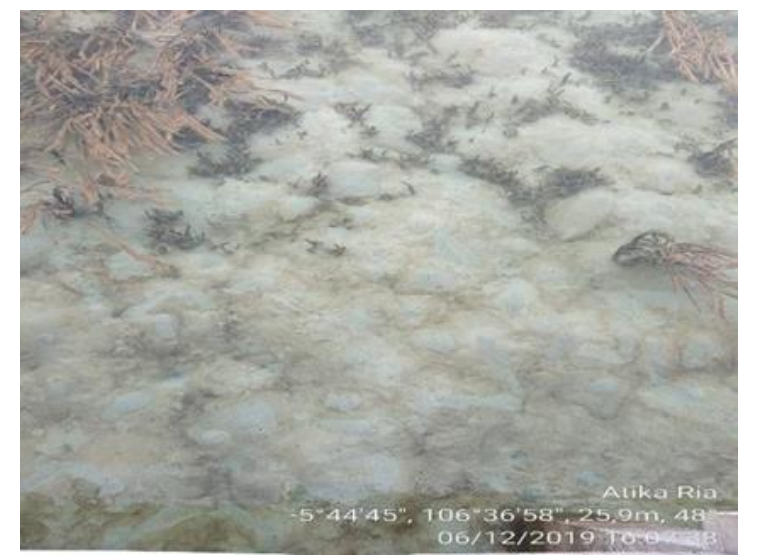

Gambar 3. Substrat Pasir.

Berdasarkan hasil pengukuran suhu, suhu permukaan di Pulau Pramuka yaitu $30^{\circ} \mathrm{C}$. Pengaruh suhu bagi lamun sangat besar, diantaranya mempengaruhi fisiologi lamun seperti laju respirasi, sintesis, dan pertumbuhan. Suhu optimal untuk pertumbuhan lamun yaitu $28-30^{\circ} \mathrm{C}$, hal tersebut menandakan bahwa pantai Pulau Pramuka adalah tempat yang tepat untuk pertumbuhan lamun sehingga lamun yang tumbuh di daerah tersebut tumbuh subur dan lebat.

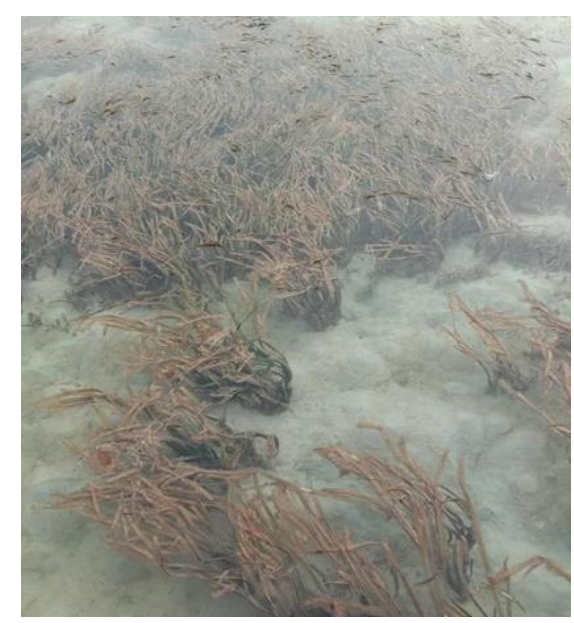

Gambar 4. Lamun Jenis Enhalus Acoroides.

\section{Jenis-jenis Fauna Assosiasi}

Terdapat berbagai jenis fauna yang berassosiasi di sekitar ekosistem padang lamun Pulau Pramuka bagian timur, biota - biota yang terdapat ditempat tersebut senantiasa hidup, berkembang biak, dan mencari makan bahkan bergantung dengan tanaman lamun tersebut.

Berbagai contoh fauna sessile (yang tidak banyak bergerak) yang hidup di sekitar ekosistem lamun yakni bulu babi (Echinoidea), teripang (Holothuroidea), dan fauna lain seperti ikan baronang (siganus guttatus), penyu (Chelonioidea), kepiting (Brachyura). Daun-daun dari lamun juga menjadi makanan bagi biota yang hidup di luar perairan contohnya burung laut.

Pada dasarnya banyak jenis ikan yang berasosiasi dengan lamun, keanekaragaman jenis (diversitas) bergantung kepada kehadiran ekosistem lain di sekitar padang lamun. 
Apakah di sekitar padang lamun terdapat ekosistem terumbu karang, mangrove, muara sungai, estuaria, dan lain-lain. Hal tersebut menentukan kehadiran jenis ikan sebagai unsur konektor padang lamun dengan ekosistem-ekosistem lain disekitarnya. Selain sebagai ekosistem yang baik untuk perkembangan berbagai jenis spesies ikan, lamun juga penting dalam mengendalikan iklim yaitu untuk menangkap karbon dan memproduksi oksigen ke udara.

\section{Padang Lamun Sebagai Daerah Asuhan dan Perlindungan Ikan dan Berbagai Biota KIKUCHI (1974) menyatakan peranan} tradisional padang lamun adalah sebagai daerah asuhan. Hasil beberapa penelitian banyak ahli, mendukung pernyataan tersebut. KIKUCHI (1964, 1974) menemukan bahwa beberapa ikan niaga, yaitu Sebastes inermis dan S. marmoratus mempergunakan padang lamun sebagai daerah asuhan. Padang lamun juga mempunyai peran sebagai perlindungan ikan. Seperti ikan baronang yang terlihat berkumpul dibalik lamun dan kepiting yang cenderung membuat gundukan berupa rumah di sela - sela pasir padang lamun.

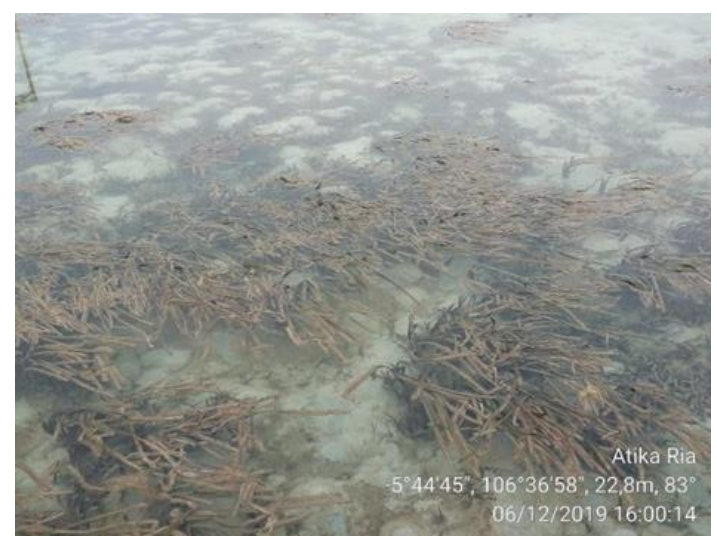

Gambar 5. Lamun dan Biota Laut.

ORTH \& HECK (1980) menemukan padang Zostera marina di Teluk Chesapeake, Amerika Serikat, kelimpahan ikan lebih tinggi di daerah yang bervegetasi (padang lamun) dari pada di daerah yang tidak bervegetasi. Kelimpahan ikan juga meningkat dengan meningkatnya suhu dan bertambahnya biomassa lamun dan sebaliknya menurun dengan menurunnya suhu dan berkurangnya biomassa lamun. Hal yang sama didapatkan oleh SPRINGER \& WOODBURN (1960) pada padang Thalassia testudinum di Tampa Bay, Florida Barat. Mereka mendapatkan bahwa naik turunnya kelimpahan ikan berkaitan dengan naik turunnya biomasa lamun dan suhu perairan.

\section{Lamun Sebagai Makanan bagi Fauna}

Secara ekologi, lamun adalah sumber utama produktivitas primer di perairan dangkal di seluruh dunia dan merupakan sumber makanan bagi seluruh organisme (dalam bentuk detritus). Perlu diketahui bahwa berbagai jenis ikan menjadikan daerah padang lamun sebagai daerah mencari makan (feeding ground).

Lamun komponen utama detritus dalam makanan di setiap laut dangkal. Tumbuhan laut ini menyediakan nutrient pada sejumlah hewan invertebrata dan ikan (PHILLIPS \& McROY 1980). Sebenarnya lamun jarang dikonsumsi langsung oleh hewan herbivora. Disamping itu lamun yang dimakan oleh hewan herbivora tersebut hanya sedikit bila dibandingkan dengan produksi lamun secara keseluruhan. Pada penelitian di bagian utara Australia, diketahui ada dua hewan herbivora besar yang secara teratur mengkonsumsi lamun untuk makanannya. Hewan herbivora tersebut adalah penyu hijau (Chelonia mydas) dan duyung (Dugong dugon).

THAYER \& ENGEL (1982) telah mengeluarkan hipotesis bahwa hewan herbivora yang berukuran besar mengembalikan secara cepat nutrient lamun yang kaya melalui produksi pencernaan/ kotorannya. Kotoran tersebut akan dikonsumsi oleh hewan detrivora lebih cepat bila dibandingkan dengan proses fisik secara normal pada proses dekomposisi.

\section{Lamun Sebagai Tempat Berburu Mangsa Bagi Ikan-Ikan Karnivora}

Tidak dapat dipungkiri bahwa lamun merupakanekosistem yang kaya akan biota laut. Biota laut yang terdapat di ekosistem lamun yakni berupa berbagai jenis ikan-ikan dan kepiting serta teripang dan lain sebagainya. Ikan-ikan seperti ini kerap kali diburu untuk dimangsa oleh ikan-ikan karnivora dan bagaikan ladang makanan bagi ikan karnivora. 


\section{Rantai Makanan pada Ekosistem Padang Lamun}

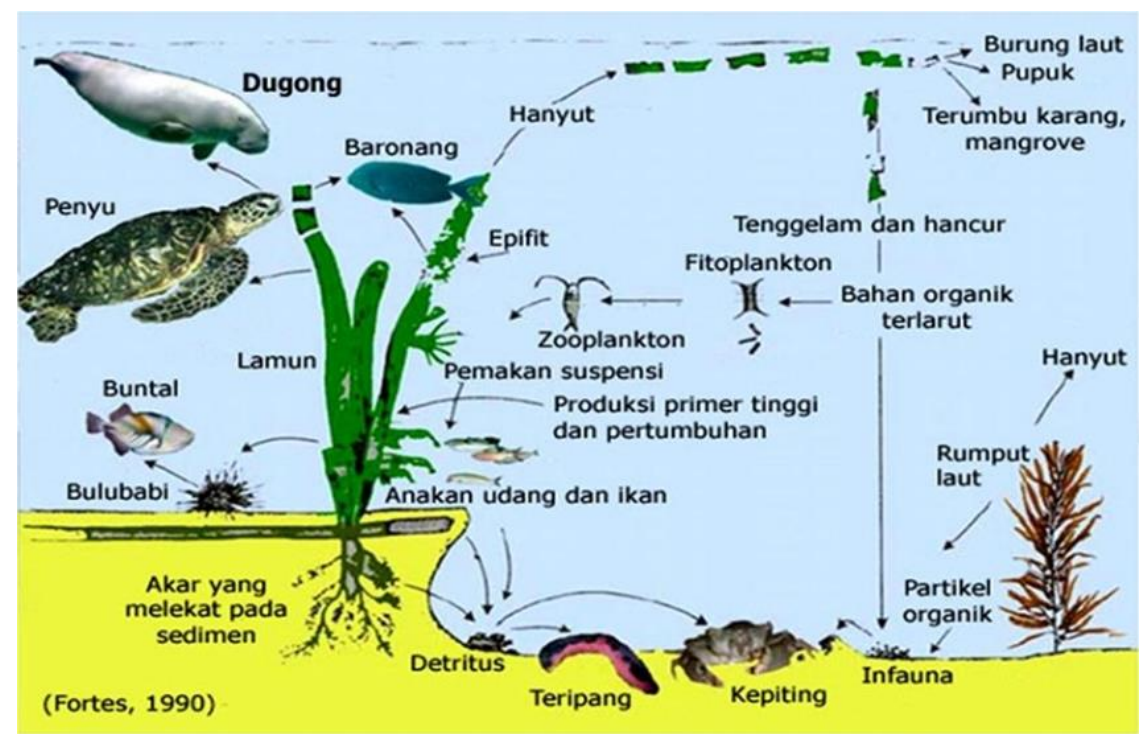

Gambar 6. Rantai Makanan dalam Ekosistem Lamun (Fortes, 1990).

Rantai makanan adalah perpindahan energi makanan dari sumber daya tumbuhan (produsen) melalui seri organisme atau melalui jenjang makanan (tumbuhan-herbivoracarnivora). Pada setiap tahap pemindahan energi, $80 \%-90 \%$ energi potensial hilang sebagai panas, karena itu langkah-langkah dalam rantai makanan terbatas 4-5 langkah saja. Dengan kata lain, semakin pendek rantai makanannya semakin besar pula energi yang tersedia (Surya, 2012). Sistem rantai makanan merupakan siklus, semua kehidupan hewan bergantung pada kemampuan tumbuhtumbuhan hijau yang memiliki klorofil untuk berfotosintesis dan fungsi dari rantai makanan adalah untuk menjaga jumlah mahluk hidup di dalamnya agar tetap seimbang.

Lamun merupakan salah satu tumbuhan laut yang berada di laut dangkal yang memiliki klorofil untuk berfotosintesis sehingga dapat memproduksi makanan yang diperlukan oleh biota-biota laut, seperti ikan baronang, bulu babi, penyu, dll. Lamun mempunyai tingkat produktivitas paling tinggi bila dibandingkan dengan ekosistem lainnya yang ada di laut dangkal, seperti ekosistem terumbu karang (Thayer et al. 1975). Lamun juga menyediakan tempat bagi hewan-hewan laut untuk berkembang biak, memijah, padang pengembalaan, dan makanan bagi beberapa jenis ikan herbivora dan ikan karang. Lamun kuga memberikan perlindungan dan tempat menempel untuk berbagai hewan dan tumbuh- tumbuhan laut. Lamun memberikan rumah bagi banuyak biota laut (Kikuchi \& Peres. 1977) sehingga peranannya menjadi sangat penting dalam ekosistem di daerah laut dangkal.

Menurut hasil pengamatan di lapangan dan analisis dari gambar 5. Dapat dijelaskan bahwa sumber energi utama pada ekosistem padang lamun adalah cahaya matahari. Cahaya tersebut digunakan oleh lamun dan fitoplankton sebagai produsen untuk berfotosintesis. Setelah itu rantai makanan tersebut dibagi menjadi 2 bagian, yaitu:

\section{Rantai makanan rerumputan (grazing food chain)}

Rantai makanan ini diawali oleh tumbuhan hijau sebagai produsen. Rantai makanan rerumputan misalnya tumbuhanherbivora-carnivora. Pada rantai makanan rerumputan ini, sumber nutriennya secara langsung adalah tumbuhan lamun itu sendiri yang daunnya dimakan oleh konsumen tingkat pertama, yaitu dugong, penyu, ikan baronang dan bulu babi. Namun kami tidak menemukan dugong di Pulau Pramuka karena dugong dapat hidup di daerah pesisir, dangkal sampai sedang dalam, dan dugong dapat hidup di perairan hangat dengan suhu minimumnya $15-17{ }^{\circ} \mathrm{C}$ sedangkan suhu permukaan air laut dangkal di Pulau Pramuka sekitar $30{ }^{\circ} \mathrm{C}$. Kemudian konsumen tingkat pertama ini dimakan oleh para predator, kecuali bulu babi, bulu babi itu 
sendiri dimakan oleh ikan buntal sebagai konsumen kedua, namun kami tidak menemukan ikan buntal di daerah timur pulau Pramuka namun kami menemukan ikan buntal di sisi barat Pulau Pramuka.

\section{Rantai makanan detritus (detritus food chain)}

Rantai makanan ini diawali oleh sisa-sisa organisme mati (detritus). Organisme yang memakan detritus disebut detrivora. Rantai makanan detritus, misalnya: detritus-detrivorapredator. Pada rantai makanan detritus ini, guguran daun dari lamun yang telah dimakan oleh konsumen tingkat satu (epifit) sebagai nutrient yang diurai oleh bakteri, kemudian detritus itu dimakan oleh cacing, udang, dan kepiting yang sebagai konsumen pertama. Setelah itu hewan-hewan tersebut dimakan oleh ikan sedang sebagai konsumen tingkat dua. Konsumen tingkat dua pun dimakan oleh ikan besar, ikan hiu dan burung laut sebagai predator yang menduduki tingkatan trofik paling tinggi memakan konsumen tingkat dua dan ikan besar sebagai konsumen tingkat tiga. Saat predator tersebut mati, maka jasadnya akan diurai oleh bakteri sebagai detrivitor yang menguraikan materi dan bangkai predator tersebut, agar detrivitor itu dikonsumsi kembali oleh konsumen pertama dan begitulah seterusnya.

Guguran daun tidak semuanya menjadi detritus, karena ada juga sebagian yang menjadi bahan organik dan bahan organik tersebut akan dimanfaatkan oleh fitoplankton yang sebagai produsen. Produsen tersebut akan dikonsumsi oleh zooplankton yang sebagai konsumen pertama. Setelah itu zooplankton tersebut akan dimakan oleh ikan kecil yang sebagai konsumen tingkat dua. Ikan kecil ini akan kembali dimakan oleh ikan-ikan sedang dan pada akhirnya mentransfer energi dan materi yang akan masuk ke dalam rantai makanan detritus. Semua bahan organik terlarut tidak hanya berasal dari dalam ekosistem tetapi ada juga yang berasal dari ekosistem terumbu karang dan mangrove.

Aktivitas manusia yang tidak bertanggung jawab dapat merusak ekosistem padang lamun dan hal itu pun dapat merusak rantai makanan yang terjadi di dalamnya. Jika saja terjadi kerusakan tingkatan trofik atau produsen akan memutuskan rantai makanan dan keseimbangannya akan terganggu. Namun, kenyataannya yang kami temukan dari hasil pengamatan di lapangan tepatnya di daerah timur di Pulau Pramuka bahwa kami jarang melihat ada kepiting, teripang, dan rumput laut karena di daerah tersebut mengalami pengerukan karena sebagian di daerah tersebut akan digunakan untuk membangun dermaga untuk kapal di Pulau Pramuka sehingga berdampak pada biota-biota laut dan ekosistem di daerah tersebut. Maka dari itu kita sebagai manusia harus merawat dan menjaga kelestarian ekosistem yang berada di laut seperti ekosistem lamun, terumbu karang, dan mangrove.

\section{SIMPULAN}

1. Sebagai sumber daya pesisir, ekosistem padang lamun memiliki multi fungsi yang sangat berfungsi untuk menunjang sistem kehidupan dan berperan penting dalam dinamika pesisir dan laut, terutama perikanan dan biota laut di pantai sehingga pemeliharaan dan rehabilitasi ekosistem padang lamun merupakan salah satu alasan untuk tetap mempertahankan keberadaan ekosistem tersebut. Ekosistem padang lamun sangat terkait dengan ekosistem di dalam wilayah pesisir seperti mangrove, terumbu karang, estauria dan ekosistem lainya dalam menunjang keberadaan biota laut, serta beberapa aspek lain seperti fungsi fisik dan sosialekonomi. Hal ini menunjukkan keberadaan ekosistem padang lamun adalah tidak berdiri sendiri, tetapi terkait dengan ekosistem sekitarnya, bahkan sangat dipengaruhi aktivitas yang berada di daratan.

2. Namun, akhir-akhir ini kondisi padang lamun semakin menyusut oleh adanya kerusakan yang disebabkan oleh aktivitas manusia. Sebagai upaya konservasi dan kelestariannya dalam rangka tetap mempertahankan lingkungan dan penggunaan yang berkelanjutan, maka dikembangkan pendekatan terpadu yang melibatkan berbagai pihak untuk perlu untuk membuat solusi tepat dalam mempertahankan fungsi ekologis dari ekosistem yaitu pengelolaan pesisir secara 
terpadu atau Integrated Coastal Management (ICM).

3. Selain itu untuk kondisi padang lamun di Pulau Pramuka sendiri kondisinya mengalami penurunan struktur komunitas padang lamun. Karena di Pulau Pramuka terjadi beberapa aktivitas antroponegik atau manusia, sehingga mengganggu kehidupan padang lamun. Seperti terdapatnya pembuangan limbah domestik dan tempat pembuangan sampah yang letaknya mendekati laut di bagian timur Pulau Pramuka. Selain itu, Pulau Pramuka juga dijadikan tempat wisata sehingga banyak ditemukan resort wisata di Pulau Pramuka. Pembangunan resort wisata serta aktivitas olahraga dan kegiatan lainnya yang berada di sekitar pantai menyebabkan padang lamun terancam rusak karena terinjak oleh kegiatan manusia tersebut. Namun di Pulau Pramuka ini terdapat konservasi padang lamun di Taman Nasional Kepulauan Seribu sehingga padang lamun di Pulau Pramuka tetap dalam keadaan baik dan terawatt dan bisa diminimalisir tingkat kerusakannya.

\section{DAFTAR PUSTAKA}

Apramilda, Riesna. 2011. Status Temporal Komunitas Lamun dan Keberhasilan Transplantasi Lamun pada Kawasan Rehabilitasi di Pulau Pramuka dan Harapan, Kepulauan Seribu, Provinsi DKI Jakarta [skripsi]. Departemen Manajemen Sumberdaya Perairan Fakultas Perikanan Dan Ilmu Kelautan, Institut Pertanian Bogor.

Assuyuti, Y. M., Rijaluddin, A. F., Ramadhan, F., Zikrillah, R. B. 2016. Estimasi Jumlah Biomassa Lamun di Pulau Pramuka, Karya dan Kotok Besar, Kepulauan Seribu, Jakarta. Depik 5(2): 85-93.

DOI: http://dx.doi.org/10.13170/depik.5.2.4 914.

Aswandy, I. 2003. Asosiasi Fauna Krustasea dengan Potongan-Potongan Lamun di Laut Dalam. Jurnal Oseana Vol XXVIII, No 4. ISSN 0216-1877.
Azkab, M.H. 1987. Percobaan Transplantasi Lamun, Cymodocea rotundata Ehrenb. \& Hempri.ex Aschers di rataan terumbu Pulau Pari, Kepulauan Seribu. Kongres Nasional Biologi VIII, Purwokerto 8-10 Oktober 1987, 20 h.

Azkab, M.H. 1988. Transplantasi Lamun, Thalassia hemprichli (Ehrenb) Aschers di rataan terumbu Pulau Pari, Kepulauan Seribu. Dalam: Teluk Jakarta; biologi, budidaya, oseanografi, geologi dan kondisi perairan (M. K. Moosa, D. P. Praseno dan Sukarno, eds.). Puslitbang Oseanologi-LIPI, Jakarta, 105-111.

Azkab, M.H. 1988. Pertumbuhan dan Produksi Lamun, Enhalus acoroides di rataan terumbu di Pari Pulau Seribu. Dalam: P3O-LIPI, Teluk Jakarta: Biologi, Budidaya, Oseanografi, Geologi dan Perairan. Balai Penelitian Biologi Laut, Pusat Penelitian dan Pengembangan Oseanologi-LIPI, Jakarta.

Azkab, M.H. 1999. Kecepatan Tumbuh dan Produksi Lamun dari Teluk Kuta, Lombok. Dalam: P3O-LIPI, Dinamika komunitas biologis pada ekosistem lamun di Pulau Lombok, Balitbang Biologi Laut, PustlibangBiologi LautLIPI, Jakarta.

Azkab, M. H. 1999. Pedoman Inventarisasi Lamun, Vol XXIV. Nomor 1: 1-16. Puslitbang Oseanologi-LIPI. Jakarta.

Balai Taman Nasional Kepulauan Seribu. 2008. Inventarisasi Padang Lamun di Taman Nasional Kepulauan Seribu. Jakarta. Halaman 44.

Bulthuis, D. A. 1987. Effect of Temperature on Photosynthesis and Growth of Seagrass. Aquatic Botany, 27: 343-367.

Citra S.U. Dewi, Soedharma, D., Kawaroe, M. 2012. Komponen Fitokimia dan Toksisitas Senyawa Bioaktif Dari Lamun Enhalus Acoroides dan 
Thalassia Hemprichii Dari Pulau

Pramuka, DKI Jakarta. Jurnal Teknologi Perikanan dan Kelautan. Vol. 3. No. 2. ISSN 2087-4871.

Coles, R. G. L. W. J. Long, J. E. Mellors, J. M. Bibby, and Roelofs. Seagrass Meadows of the Eastern Gulf of Carpentaria. QDPI Information Series.

Coles, R. G. L, W. J. Long, R. A. Watsom, and K. J. Derbyshire. 1993. Distribution of Seagrass and Their Fish and Penaeid Prawn Communities in Cairns Harbour a Tropical Estuaria, Northern Queensland, Australia. In Tropical Seagrass Ecosyestems; Structure and Dynamics in the Indo-West Pacific. Australian Journal and Freshwater Research, 44: 193-210.

Dennison, W. C. 1987. Effects of Light on Seagrass Photosynthesis, Growth and Depth Distribution. Aquatic Botany, 27: 15-26.

Dennison, W. C., R. J. Orth, K. A. Moore, J. C. Stevenson, V. Carter, S. Kollar, P. W. Bergstrom, and Batiuk, R.A. 1993. Assesing Water Quality with Submersed Aquatic Vegetation: Habitat Requirements as Barometers of Chesapeake Bay health. Bio-Science 42(2): 86-94.

Dore, I., and C. Frimodt. 1987. An illustrated guide to shrimp of the world. Osprey Books, Huntington, N.Y. 229 pp.

English, S., C. Wilkinson dan V. Baker. 1994. Survey Manual for Tropical Marine Resources. ASEAN Australia Marine Science Project: Living Coastal Resources.

Erftemeijer, P. L. A. 1994. Differences in Nutrient Concentration and Resources between Seagrass Communities on Carbonate and Terrigenous Sediments in South Sulawesi, Indonesia. Bulletin of Marine Science 54(2), 403-419.
Feryatun F., Hendrarto, B., Widyorini, N. 2012. Kerapatan dan Distribusi Lamun (Seagrass) Berdasarkan Zona Kegiatan yang Berbeda di Perairan Pulau Pramuka, Kepulauan Seribu. Journal of Management of Aquatic Resources. Halaman 1-7.

Fortes, M. D. 1990. Seagrasses: A Resource Unknown in the ASEAN Region. Association of Southeast Asian Nations/United States Coastal Resources Management Project Education Series 6.

Gulland, J. A. and J. R. Brian (Editor). 1984. Penaeid Shrimps-their Biology and Management. Selected papers presented at the workshop on the scientific basis for the management of penaeid shrimp held at Key West, Florida, U.S.A. Fishing News Books Limited.

Lanyon, J., C. J. Limpus, and H. Marsh. 1989. Dugongs and Turtles; Grazers in the Seagrass System. In Biology of Seagrass. A treatles on the Biology of Seagrass with a Special reference to the Australian Region. (Eds. A.W. D. Larkum, A. J. McComb and S. A. Shepherd).

Lanyon, J. 1986. Seagrasses of the Great Barrier Reef. Great Barrier Reef Marine Park Authority Special Publication Series (3).

Mellors, J. E., H. Marsh, and R. G. Coles. 1993. Intraannual Change in Seagrass Standing Crop, Green Island, Northern Queensland. In Tropical Seagrass Ecosystems; Structure and Dynamics in the Indo-West Pacific. Australian Journal of Marine and Freshwater Research, 44: 33-42.

Orth, R. J. 1977. Effect of Nutrient Enrichment on Growth of Eelgrass Zostera marina in the Chesapeake Bay, Virginia, USA. Marine Biology 44, 187- 194. 
Phillips, R. C., and E. G. Menez. 1988. Seagrasses. Smithsonian Contribution to tha Marine Sciences. Number 34. Smithsonian Institution Press. Washington D.C.

Poiner, I. R., D. I. Walker, and R. G. Coles. 1989. Regional Studies-Seagrass of Tropical Australia. In Biology of Seagrass: A Treatise on the Biology of Seagrass with Special Reference to the Australian Region. (Eds A.W.D. Larkum, A.J. McComb and S.A. Sheperd) Chapter 10, pp. 279-296 (Elsevier: New York).
Rashed, M. A., L. Long, W. J. McKenzie, L. J. Roder, C. A. Roelofs, A. J. Coles and R.G. Coles. 1995. Port of Karumbu. Seagrass Monitoring Baseline Surveys. EcoPorts onograph Series Num. 4.

Sjafrie, N. D. M., Iswari, M. Y., Suyarso, Rahmat. 2017. Status Padang Lamun Indonesia 2017. Puslit OseanografiLIPI, Bibliografi: hlm. 23.

Tomascik, T., A. J. Mah, A. Nontji, and M. K. Moosa. 1997. The Ecology of the Indonesian Seas. Part Two. The Ecology of Indonesia Series. Volume VIII. 